\title{
Perivascular and Diffuse Lymphocytic Inflammation are not Specific for Failed Metal-on-metal Hip Implants
}

\author{
Takaaki Fujishiro MD, PhD, Dirk Jan F. Moojen MD, PhD, \\ Naomi Kobayashi MD, PhD, Wouter J. A. Dhert MD, PhD, FBSE, \\ Thomas W. Bauer MD, PhD
}

Received: 24 February 2010/ Accepted: 13 October 2010/Published online: 29 October 2010

(C) The Author(s) 2010. This article is published with open access at Springerlink.com

\begin{abstract}
Background Several studies suggest that histologic findings from tissues obtained at revision arthroplasty for failed metal-on-metal (MOM) total hip implants may reflect an immune reaction to particles or ions in some patients. However, only a limited number of cases without MOM implants were reported as controls in those studies.

Questions/purposes The purpose of this study is to better define the extent and distribution of morphologic features attributed to an immune reaction in tissues sampled at revision surgery for failed nonMOM THA.

Patients and Methods As part of a multicenter, prospective study, we reviewed 612 capsular and interface tissues obtained from 130 patients at revision THA. The samples
\end{abstract}

Each author certifies that he or she has no commercial associations (eg, consultancies, stock ownership, equity interest, patent/licensing arrangements, etc) that might pose a conflict of interest in connection with the submitted article.

Each author certifies that his or her institution approved the human protocol for this investigation and that all investigations were conducted in conformity with ethical principles of research, and that informed consent for participation in the study was obtained. This work was performed at the Cleveland Clinic Foundation.

T. Fujishiro, N. Kobayashi, T. W. Bauer $(\square)$

Departments of Pathology and Orthopaedic Surgery,

The Cleveland Clinic, L25, 9500 Euclid Avenue,

Cleveland, OH 44195, USA

e-mail: osteoclast@aol.com

D. J. F. Moojen, W. J. A. Dhert

Department of Orthopaedics, University Medical Center,

Utrecht, The Netherlands

T. Fujishiro

Department of Orthopaedic Surgery, Kobe University Graduate

School of Medicine, 7-5-1 Kusunoki-Cho Chuo-Ku, Kobe,

Hyogo 650-0017, Japan were selected from periacetabular regions (154 samples from 103 patients), femoral implant/cement-bone interface (154 samples from 79 patients), and from areas of the joint capsule that had an intraoperative gross appearance suggesting the possibility of either infection or metallosis (256 samples from 129 patients). All patients had more than one sample obtained. The extent and distribution of lymphocytes and plasma cells, acute inflammation, and visible particles of debris were graded using criteria similar to those described to grade inflammation around failed MOM implants.

Results We identified perivascular lymphocytes in 111 biopsy samples taken from 65 (50\%) of 130 patients, and in 87 specimens from 57 (53\%) of 107 patients thought to have aseptic loosening. Diffusely distributed lymphocytes were identified in $86(66 \%)$ of 130 patients, and in $66(62 \%)$ of the 107 hips with aseptic loosening, although few had the highest grade of inflammation. Increasing extent of diffuse and perivascular lymphocytes correlated with increasing extent of metal particles.

Conclusions Mild lymphocytic inflammation, diffuse and especially perivascular, is common in tissues around failed nonMOM implants. Although extensive inflammation in an inflammatory pseudotumor pattern is rare, it does occur in some cases of failed metal-polyethylene hip arthroplasties. The importance of inflammation is unknown, but the extent of diffuse inflammation shows a positive correlation with metal debris, so it could reflect a reaction to particles or ions in some patients.

\section{Introduction}

Currently available MOM implants have the potential advantage of reducing wear compared with metal-onpolyethylene articulating hips [1]. However, the particles 
produced by MOM constructs are small $[8,11]$, and their dissolution results in measurable increases in cobalt and chromium ions in the serum and urine of patients with MOM bearings $[6,12,16]$. In addition, several studies have described diffusely distributed and perivascular lymphocytes in tissue membranes around failed MOM implants apparently not associated with infection, and the authors have interpreted this inflammation as an immunologic reaction against metal ions or metal particles associated with those articulations [4, 5, 7, 10, 12, 15-17]. The presence of perivascular lymphocytes has been especially emphasized [7, 10, 12, 17], and some authors have described a pattern of inflammation as "unique" to failed MOM implants [5, 17]. However, those studies contained relatively few nonMOM control samples. For example, Davies et al. [7] reported absent "perivascular lymphocytic cuffs" and absent plasma cells in 100\% of 19 metal-onpolyethylene control cases, and Park et al. included no nonMOM controls [14]. Without a comparable number of nonMOM controls, it has been difficult to determine the importance of chronic inflammation, and especially of perivascular lymphocytes in the MOM cases.

The purposes of this study were to determine (1) the extent and distribution of inflammatory cells, and (2) to test the potential association of cells believed to be associated with immune reactions to debris particles in joint capsular and interface tissues of failed, nonMOM hip implants.

\section{Patients and Methods}

As part of an IRB-approved, prospective, multicenter study intended to help determine the frequency of periimplant infections in patients thought to have experienced aseptic loosening [13], participating surgeons from six medical centers in The Netherlands were asked to obtain multiple specimens from each patient undergoing revision arthroplasty during the course of the study. One year followup of all patients after revision arthroplasty helped define the predictive value of various tests to diagnose unsuspected infection [13]. That initial cohort included 692 tissue samples from 148 patients. The design of the current study was to use a large subset of specimens from the patients with failed nonMOM implants from that wellcharacterized clinical cohort to characterize the inflammatory patterns thought by some to represent an immune reaction to MOM implants. We excluded nine patients with failed MOM implants or with implants of unknown composition from the original group because the focus of our study was to study inflammation in nonMOM implant failures. We excluded an additional nine patients whose diagnosis at primary hip arthroplasty was inflammatory arthropathy. These patients were excluded because the chronic inflammation characteristic of an inflammatory arthropathy would render interpreting periimplant inflammation meaningless. The remaining cohort therefore included 612 samples from 130 patients.

As noted above, the prospective sampling protocol recommended obtaining biopsy specimens from several different sites. More specifically, surgeons were encouraged to obtain samples from near the acetabular component, the femoral implant or cement/bone interface, and from two other areas, with preference to sampling areas that by gross appearance suggested the possibility of metallosis or infection or corresponded to areas of radiographic osteolysis. Therefore, the 612 samples included 256 biopsy specimens from areas thought by the surgeons to have a suspicious gross appearance, 202 samples from near the acetabular components, and 154 samples from the femoral implant/cementbone interface. All specimens were immediately preserved in $10 \%$ buffered formalin, dehydrated, embedded in paraffin according to standard techniques, and sections were stained with hematoxylin and eosin at each participating institution.

Microscope slides were submitted to a reference laboratory where they were reviewed by two of the authors who were not treating surgeons (TWB and TF). The extent and distribution of inflammatory cells were graded in a manner similar to that described in evaluations of tissues around failed MOM implants (Table 1) [7, 17]. The types of

Table 1. Grading criteria used in this study

\begin{tabular}{|c|c|c|}
\hline Grade & Criteria & Interpretation \\
\hline $0+$ & Neutrophils Absent & Not infected \\
\hline $1+$ & $\begin{array}{l}1 \text { cell per } 10 \text { hpfs } \\
(\text { high power }(\times 400) \text { fields })\end{array}$ & Not infected \\
\hline $2+$ & 2 to 5 cells per $10 \mathrm{hpfs}$ & Not infected \\
\hline $3+$ & 6 to 10 cells per $10 \mathrm{hpfs}$ & $\begin{array}{l}\text { Borderline probably } \\
\text { not infected }\end{array}$ \\
\hline $4+$ & $\begin{array}{l}>10 \text { cells per } 10 \text { hpfs but less than } \\
3 \text { hpfs with } 5 \text { or more cells }\end{array}$ & $\begin{array}{l}\text { Borderline probably } \\
\text { infected }\end{array}$ \\
\hline \multirow[t]{2}{*}{$5+$} & $\begin{array}{l}5 \text { or more cells per hpf in at least } \\
3 \text { fields }\end{array}$ & Infected \\
\hline & General lymphocytes or plasma cells & \\
\hline $0+$ & $<10$ cells per hpf & \\
\hline $1+$ & 11 to 30 cells per hpf & \\
\hline $2+$ & 31 to 50 cells per hpf & \\
\hline $3+$ & 51 to 100 cells per hpf & \\
\hline \multirow[t]{2}{*}{$4+$} & $>100$ cells per $\mathrm{hpf}$ & \\
\hline & Layers of lymphocytes & $\begin{array}{l}\text { Number of vessels } \\
\text { involved }\end{array}$ \\
\hline $0+$ & Absent & Absent \\
\hline $1+$ & 1 to 3 layers around vessels per hpf & 1 to 2 \\
\hline $2+$ & 4 to 10 layers around vessels per hpf & 3 to 6 \\
\hline $3+$ & $>10$ layers around vessels per hpf & 7 to 10 \\
\hline $4+$ & & $>10$ \\
\hline
\end{tabular}


particles visible by light microscopy (probable metal, polyethylene, and zirconium from bone cement) also were recorded.

The areas with the most inflammation were reviewed at $\times 400$ magnification, and acute inflammation was graded by counting the number of neutrophils (Table 1). We interpreted a specimen to be suggestive of infection if it contained Grade 4+ or Grade 5+ neutrophils located beneath the surface of the membrane according to previously described methods [2,3]. Neutrophils were identified in 63 specimens from 31 of the 130 patients. Forty-five of these 63 specimens (7\% of the 612 total specimens) from 21 patients had Grade 4+ or Grade 5+ neutrophils, and therefore were interpreted as having histologic features suggestive of ongoing infection. Two other patients had the clinical diagnosis of probable infection, but their tissue specimens did not show acute inflammation. The remaining 500 specimens from 107 patients were considered to be from hips in which aseptic loosening had developed.

We used the five high power fields (hpf, $\times 400)$ with the most nonperivascular lymphocytes and plasma cells to quantify the maximum chronic inflammation of the tissue as follows: Grade $0=$ fewer than 10 cells per hpf; Grade $1+=11$ to 30 cells per hpf; Grade $2+=31$ to 50 cells per hpf; Grade $3+=451$ to 100 cells per hpf; and Grade $4+=$ more than 100 cells per hpf.

The number of vessels with perivascular inflammation and the magnitude of that inflammation were graded. First, the areas with the most perivascular inflammation were reviewed at $\times 40$ magnification and the number of vessels with perivascular inflammation was graded as follows: Grade $0=$ absent; Grade $1+=1$ to 2 vessels; Grade $2+=3$ to 6 vessels; Grade $3+=7$ to 10 vessels; and Grade $4+=$ more than 10 vessels. The five microscopic fields with the most perivascular inflammation were reviewed at $\times 100$ magnification, and the total number of vessels was counted. The number of vessels that had perivascular lymphocytes was recorded, and the percentage of vessels with perivascular lymphocytes was calculated. Then the average number of layers of perivascular lymphocytes was graded: Grade $0=$ absent; Grade $1+=1$ to 3 layers of lymphocytes (Fig. 1A); Grade $2+=4$ to 10 layers of lymphocytes (Fig. 1B); and Grade $3+=$ more than 10 layers of lymphocytes (Fig. 1C).

Particles morphologically consistent with metal, polyethylene, or zirconium (from bone cement), and the macrophage reaction to those particles were recorded using the scale described by Willert et al. [17]

Between the two authors who graded inflammation, interobserver reproducibility was good, however, we did not grade tissue organization (ie, layers of necrosis and fibrosis as described by Willert et al. [17] and more recently by Campbell et al. [5]), because we had very high variability between observers and among multiple different specimens from the same patient, rendering this observation meaningless. The Kruskal-Wallis and post hoc Scheffe statistical tests were used to compare the extent and distribution of each type of inflammation among the capsular,
Fig. 1A-C (A) Grade 1+ perivascular lymphocytes surrounded by macrophages containing metal particles (Stain: hematoxylin and eosin; original magnification: $\times 400$ ), (B) Grade 2+ perivascular lymphocytes (Stain: hematoxylin and eosin; original magnification: $\times 200$ ), and (C) Grade 3+ perivascular inflammation (Stain: hematoxylin and eosin; original magnification: $\times 100$ ).

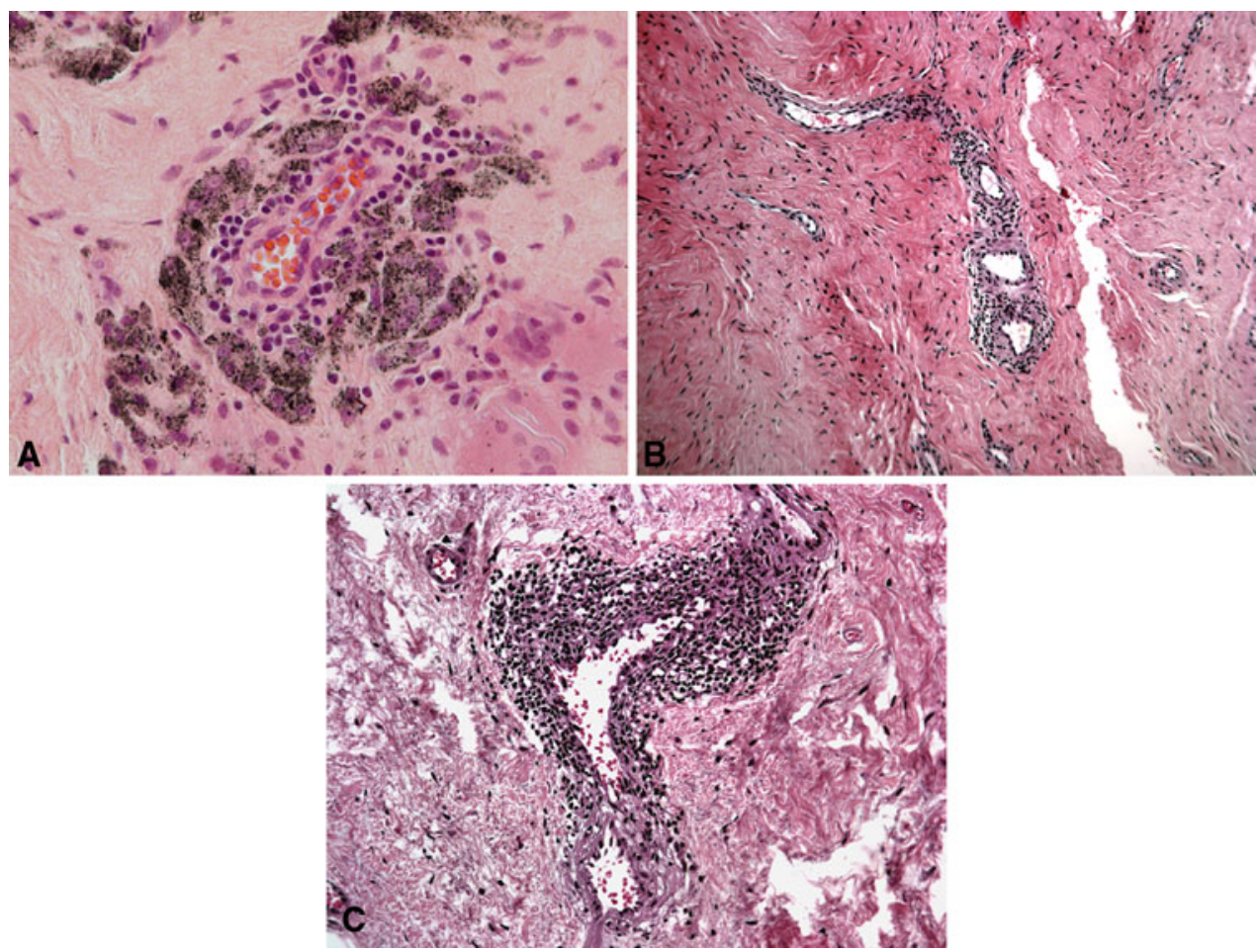


acetabular, and femoral specimens. Spearman's rank correlation coefficient was used to test correlations between one type of inflammation and another. Chi square test was used to test for an association between visible metal or zirconium particles and lymphocytes.

\section{Results}

Diffuse lymphocytes (ie, not perivascular) were identified in 151 specimens from 66 (62\%) of the 107 patients thought to have experienced aseptic loosening, and were even more common when patients with periprosthetic infections were included in the entire group (66\% of 130 patients) (Fig. 2). have aseptic loosening had Grade +3 or +4 diffuse lymphocytes. Plasma cells were common in patients with periprosthetic infections, and also were found in seven (7\%) of the 107 patients thought to have aseptic loosening. Perivascular lymphocytes were identified in $57(53 \%)$ of the 107 patients with aseptic loosening, and in $50 \%$ of the entire group of 130 patients (Table 2). Many samples also showed a macrophage reaction to particles of debris, and probable metal particles were identified in 198 of the 500 specimens from the 107 patients who had aseptic loosening. Zirconium particles from bone cement were identified in 189 of the 500 specimens. Perivascular lymphocytes were identified in 47 of the 198 specimens that also had visible metal particles (Fig. 1A), and in 40 of 302 specimens that did not have visible metal particles. Perivascular lymphocytes were present in 34 of 183 specimens that had visible zirconium particles and in 53 of 317 specimens without visible zirconium particles. Increased diffuse lymphocytes were identified in 75 of 198 specimens that also had visible metal particles, and in 76 of 302 specimens that did not have visible metal particles. Biopsy specimens from 12 of the 107 patients thought to

The extent of diffuse lymphocytes in the overall group of 130 patients, and in the 107 patients thought to have aseptic loosening correlated with the overall extent of macrophage reaction to particles $(p<0.001)$ and with perivascular lymphocytes $(\mathrm{p}<0.001)$ and plasma cells $(\mathrm{p}<0.001)$. We found a correlation $(\mathrm{p}<0.001)$ between increasing layers of lymphocytes around each vessel and the number of vessels with perivascular inflammation. The extent of perivascular lymphocytes did not correlate with the extent of neutrophils or plasma cells in the 107 patients who had aseptic loosening, but the amount of perivascular inflammation correlated with the number of neutrophils $(\mathrm{p}=0.003)$ and plasma cells $(\mathrm{p}<0.001)$ in the larger group of 130 patients that included patients who underwent revision surgery for infection, suggesting an association between perivascular inflammation and infection. The extent of macrophage reaction to particles correlated with the extent of diffuse and perivascular lymphocytes (Table 3). The presence of perivascular lymphocytes correlated with visible metal particles $(\mathrm{p}=0.025)$ but not with zirconium particles $(\mathrm{p}=0.28)$. We observed a correlation $(p=0.0025)$ between increased diffuse lymphocytes and visible metal particles suggesting an association between this pattern of inflammation and metal debris (Table 4).

Table 2. Extent and distribution of perivascular lymphocytes in 107 patients thought to have aseptic loosening

\begin{tabular}{lcccc}
\hline Grade & Capsule & Acetabulum & Femur & Total \\
\hline $0+$ & $165(78.2 \%)$ & $149(86.1 \%)$ & $100(86.2 \%)$ & $413(82.6 \%)$ \\
$1+$ & $38(18.0 \%)$ & $15(8.7 \%)$ & $12(10.3 \%)$ & $66(13.2 \%)$ \\
$2+$ & $7(3.3 \%)$ & $9(5.2 \%)$ & $3(2.6 \%)$ & $19(3.8 \%)$ \\
$3+$ & $1(0.5 \%)$ & $0(0 \%)$ & $1(0.9 \%)$ & $2(0.4 \%)$ \\
Total & 211 & 173 & 116 & 500 \\
\hline
\end{tabular}
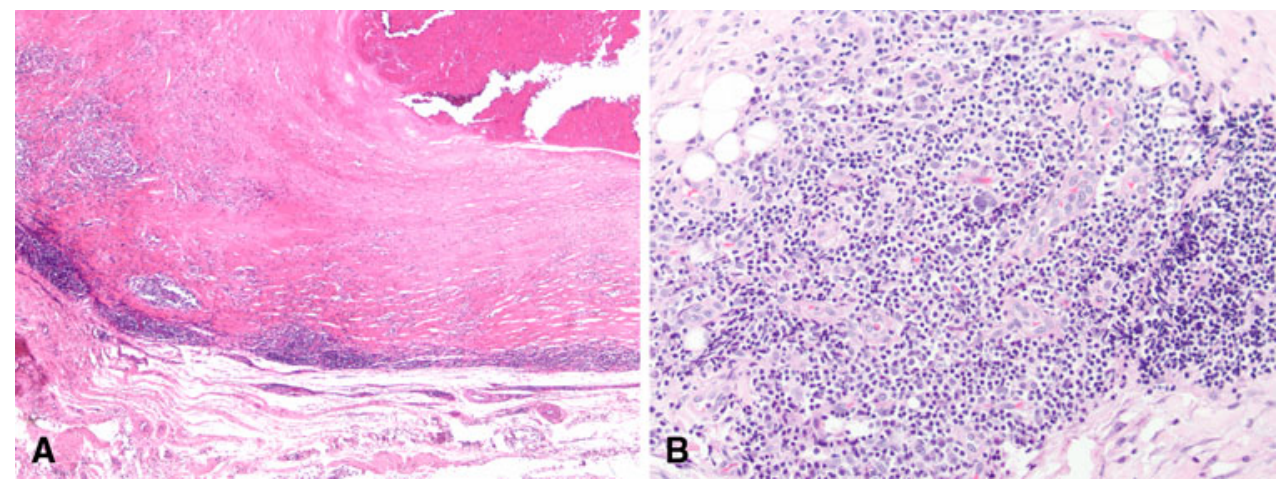

Fig. 2A-B (A) Grade 4+ diffusely distributed lymphocytes (more than 100 cells per high-power field) in a membrane around a failed, nonMOM hip arthroplasty are shown (Original magnification: $\times 100$ ).

(B) This is another example of marked chronic inflammation including lymphocytes and plasma cells, with diffuse and perivascular distribution in a case of nonMOM arthroplasty thought to have developed aseptic loosening (Original magnification: $\times 400$ ). 
Table 3. Correlations ( $\mathrm{p}$ values) between each type of cellular reaction

\begin{tabular}{|c|c|c|c|}
\hline Index observation & Tested variable & $\begin{array}{l}\text { All hips (aseptic and possibly } \\
\text { infected) }(\mathrm{n}=130)\end{array}$ & $\begin{array}{l}\text { Hips thought to have aseptic } \\
\text { loosening }(\mathrm{n}=107)\end{array}$ \\
\hline \multirow[t]{6}{*}{ Neutrophils } & Lymphocytes & $<0.0001$ & 0.35 \\
\hline & Plasma cells & $<0.0001$ & 0.041 \\
\hline & $\begin{array}{l}\text { Layers (ie, number of layers } \\
\text { of perivascular lymphocytes) }\end{array}$ & $<0.0001$ & 0.43 \\
\hline & $\begin{array}{l}\text { Vessel (number) (ie, number of vessels } \\
\text { with perivascular lymphocytes) }\end{array}$ & 0.0003 & 0.44 \\
\hline & $\begin{array}{r}\text { Vessel (\%) (ie, percent of vessels } \\
\text { with perivascular lymphocytes) }\end{array}$ & 0.0004 & 0.46 \\
\hline & Debris particles & 0.0068 & 0.97 \\
\hline \multirow[t]{5}{*}{ Lymphocytes } & Plasma cells & $<0.0001$ & $<0.0001$ \\
\hline & Layers & $<0.0001$ & $<0.0001$ \\
\hline & Vessel (number) & $<0.0001$ & $<0.0001$ \\
\hline & Vessel $(\%)$ & $<0.0001$ & $<0.0001$ \\
\hline & Debris particles & $<0.0001$ & $<0.0001$ \\
\hline \multirow[t]{4}{*}{ Plasma cells } & Layers & $<0.0001$ & 0.38 \\
\hline & Vessel (number) & $<0.0001$ & 0.36 \\
\hline & Vessel (\%) & $<0.0001$ & 0.35 \\
\hline & Debris particles & 0.71 & 0.21 \\
\hline \multirow[t]{3}{*}{ Layers } & Vessel (number) & $<0.0001$ & $<0.0001$ \\
\hline & Vessel (\%) & $<0.0001$ & $<0.0001$ \\
\hline & Debris particles & 0.0004 & $<0.0001$ \\
\hline \multirow[t]{2}{*}{ Vessel (number) } & Vessel (\%) & $<0.0001$ & $<0.0001$ \\
\hline & Debris particles & 0.0002 & $<0.0001$ \\
\hline Vessel (\%) & Debris particles & 0.0001 & $<0.0001$ \\
\hline
\end{tabular}

Table 4. Chi square for correlations

\begin{tabular}{|c|c|c|c|}
\hline Index observation & $\begin{array}{l}\text { Lymphocytes }+ \\
\text { Perivascular }\end{array}$ & $\begin{array}{l}\text { Lymphocytes - } \\
\text { Perivascular }\end{array}$ & Total \\
\hline Metal particles + & 47 & 151 & 198 \\
\hline Metal particles - & 40 & 262 & 302 \\
\hline $\begin{array}{l}\text { Total } \\
\mathrm{p}=0.025\end{array}$ & 87 & 413 & 500 \\
\hline Zirconium particles + & 34 & 149 & 183 \\
\hline Zirconium particles - & 53 & 264 & 317 \\
\hline \multirow{2}{*}{$\begin{array}{l}\text { Total } \\
\mathrm{p}=0.28\end{array}$} & 87 & 413 & 500 \\
\hline & Diffuse & Diffuse & Total \\
\hline Metal particles + & 75 & 123 & 198 \\
\hline Metal particles - & 76 & 226 & 302 \\
\hline $\begin{array}{l}\text { Total } \\
\mathrm{p}=0.0025\end{array}$ & 151 & 349 & 500 \\
\hline Zirconium particles + & 64 & 119 & 183 \\
\hline Zirconium particles - & 87 & 230 & 317 \\
\hline $\begin{array}{l}\text { Total } \\
\mathrm{p}=0.077\end{array}$ & 151 & 349 & 500 \\
\hline
\end{tabular}

\section{Discussion}

Several reports have described patients with failed MOM implants who had early implant loosening or unexplained hip pain $[4,15,16]$. Several other reports have described tissues around failed MOM hip implants as showing patterns of inflammation that have been interpreted as representing an immune reaction to metal particles or ions $[7,10,12,14,16,17]$. The morphologic features of that inflammatory reaction reportedly include loss of surface synovial lining with fibrin deposition, lymphocytes in diffuse and perivascular distributions, and loss of normal tissue arrangement [5]. Some of these findings have been described as unique [5, 17], but the apparent specificity of these observations has not been tested in comparable-sized cohorts of failed nonMOM cases. The purposes of this study are to evaluate a large sample of nonMOM cases to document the extent and distribution of patterns of inflammation interpreted as representing a hypersensitivity reaction, and to test if those patterns of inflammation correlate with metal versus zirconium debris, or with infection.

There were several limitations to this study. First, perivascular lymphocytes are commonly attributed to a 
systemic reaction, such as a drug reaction, but we were unable to obtain complete medical records that might indicate other causes of systemic inflammation. The medications ingested by these patients are not known, but mild perivascular inflammation could have been caused by a clinically unrecognized drug reaction or other systemic immune response in some of these patients. Second, we did not attempt to digest tissue samples to quantify the amount or type of debris. Our correlation between the amount and distribution of inflammation and visible debris particles indicates an association only, and does not prove a causal relationship. We recognize that these cases contain many particles too small to be identified by light microscopy. Further studies that quantify particles and identify more precisely the composition of debris and soluble ions may better define a potential immune reaction.

Other authors have acknowledged that low concentrations of nonperivascular lymphocytes are common in membranes around failed hip implants of all types [5]. However, Davies et al. [7] reported "lymphocyte cuffs" in membranes around 17 of 25 cases of failed MOM hips, but in none of 19 metal-PE cases, suggesting specificity for metal-metal failures. We commonly see perivascular lymphocytes in synovial tissue obtained at primary arthroplasty, and perivascular inflammation was relatively common in this group of failed, nonMOM hips. Some of the foci of perivascular inflammation in our study were small (less than a three-cell-thickness layer), but in 21 of the 87 specimens with perivascular inflammation the lymphocytes comprised more than a four-cell-thickness layer. This illustrates that perivascular lymphocytes (so-called "aseptic lymphocytic vasculitis-associated lesion" [5]) are not specific for MOM hips. Relatively low concentrations of diffusely distributed lymphocytes also were common in our study specimens. Although Grade 4+ inflammation, using the grading system of Willert et al. [17] was unusual, we found Grade 3+ or 4+ at least focally in $11 \%$ of the 107 patients with aseptic loosening of nonMOM hips, again illustrating the lack of specificity of this observation for MOM failures. Some investigators have attempted to determine whether morphologic features suggestive of an immune reaction might be related to the amount of cobalt and chromium released from the articulating surfaces of MOM implants [10, 12, 17]. With the number of samples analyzed, no correlation between lymphocytes and metal debris was identified in those studies. However, we found a positive association between the presence of metal particles visible by light microscopy and diffuse and perivascular lymphocytes. Although six of our specimens which had no visible debris particles and no evidence of infection had perivascular inflammation, the findings still suggest that lymphocytes could be related to metal debris or ions, as there is potential metal wear from hip implants of all designs in this study.

A possible role of plasma cells in an immune reaction to MOM implants has been suggested by some authors. For example, Davies et al. reported plasma cells in tissue specimens from 10 of 25 failed MOM hips but none of 19 failed nonMOM cases [7], again suggesting specificity to MOM failures. However, in our study plasma cells were identified in $18(14 \%)$ of the entire group of 130 patients, and in seven $(6 \%)$ of the 107 patients thought to have aseptic loosening. These observations illustrate that plasma cells often are increased in a periprosthetic infection, and also can be present in a relatively small proportion of nonMOM hips that are thought to have aseptic loosening.

A discussion of the immunology of ion or particleinduced bone resorption is beyond the scope of this observational study, but the role of the specific immune system in particle-induced osteolysis is controversial. Jiranek et al. [9] observed a macrophage and giant cell inflammatory reaction to particles of polymethylmethacrylate debris in mice with various levels of immune deficiencies, documenting that lymphocytes may not be necessary in a pure, nonspecific particle reaction. Lymphocytes were essentially absent from some of the cases in our study, but it seems likely that the cell biology of an inflammatory reaction is influenced partly by the composition of the particles (eg, polyethylene versus metal or mixed particles).

The magnitude of chronic inflammation in our failed nonMOM cases usually was less than in most reported cases of failed MOM implants, but in general the patterns of inflammation were similar in some cases, and in a few cases the histologic findings seem essentially identical to the so-called inflammatory pseudotumor morphology described for MOM cases [5]. The causes of these different patterns of inflammation are unknown, but the association between the extent of inflammation and visible metal particles (but not zirconium particles) supports the concept of an immune reaction to metal, and illustrates that the process is not specific to MOM constructs.

Acknowledgments We thank the participating centers (University Medical Center Utrecht, H.Ch. Vogely; Saint Maartensclinic, G.G. van Hellemondt; Medical Center Alkmaar, B.J. Burger; Isala Clinics, N.J.A. Tulip; University Medical Center Sint Radboud, B.W. Schreurs; University Hospital Maastricht, G.H.I.M. Walenkamp; and OLVG Amsterdam, F.R.A.J. de Meulemeester) for including patients and providing samples.

Open Access This article is distributed under the terms of the Creative Commons Attribution Noncommercial License which permits any noncommercial use, distribution, and reproduction in any medium, provided the original author(s) and source are credited. 


\section{References}

1. Affatato S, Leardini W, Jedenmalm A, Ruggeri O, Toni A. Larger diameter bearings reduce wear in metal-on-metal hip implants. Clin Orthop Relat Res. 2007;456:153-158.

2. Athanasou NA, Pandey R, de Steiger R, Crook D, Smith PM. Diagnosis of infection by frozen section during revision arthroplasty. J Bone Joint Surg Br. 1995;77:28-33.

3. Bauer TW, Parvizi J, Kobayashi N, Krebs V. Diagnosis of periprosthetic infection. J Bone Joint Surg Am. 2006;88:869-882.

4. Bohler M, Kanz F, Schwarz B, Steffan I, Walter A, Plenk H Jr, Knahr K. Adverse tissue reactions to wear particles from Co-alloy articulations, increased by alumina-blasting particle contamination from cementless Ti-based total hip implants: a report of seven revisions with early failure. J Bone Joint Surg Br. 2002;84:128-136.

5. Campbell P, Ebramzadeh E, Nelson S, Takamura K, De Smet K, Amstutz HC. Histological features of pseudotumor-like tissues from metal-on-metal hips. Clin Orthop Relat Res. 2010;468: 2321-2327.

6. Cuckler JM. The rationale for metal-on-metal total hip arthroplasty. Clin Orthop Relat Res. 2005;441:132-136.

7. Davies AP, Willert HG, Campbell PA, Learmonth ID, Case CP. An unusual lymphocytic perivascular infiltration in tissues around contemporary metal-on-metal joint replacements. J Bone Joint Surg Am. 2005;87:18-27.

8. Firkins PJ, Tipper JL, Saadatzadeh MR, Ingham E, Stone MH, Farrar R, Fisher J. Quantitative analysis of wear and wear debris from metal-on-metal hip prostheses tested in a physiological hip joint simulator. Biomed Mater Eng. 2001;11:143-157.

9. Jiranek W, Jasty M, Wang JT, Bragdon C, Wolfe H, Goldberg M, Harris W. Tissue response to particulate polymethylmethacrylate in mice with various immune deficiencies. J Bone Joint Surg Am. 1995;77:1650-1661.

10. Korovessis P, Petsinis G, Repanti M, Repantis T. Metallosis after contemporary metal- on-metal total hip arthroplasty: five to nineyear follow-up. J Bone Joint Surg Am. 2006;88:1183-1191.

11. MacDonald SJ. Metal-on-metal total hip arthroplasty: the concerns. Clin Orthop Relat Res. 2004;429:86-93.

12. Milosev I, Trebse R, Kovac S, Cor A, Pisot V. Survivorship and retrieval analysis of Sikomet metal-on-metal total hip replacements at a mean of seven years. J Bone Joint Surg Am. 2006;88: $1173-1182$.

13. Moojen DJ, van Hellemondt G, Vogely HC, Burger BJ, Walenkamp GH, Tulp NJ, Schreurs BW, de Meulemeester FR, Schot CS, van de Pol I, Fujishiro T, Schouls LM, Bauer TW, Dhert WJ. Incidence of low-grade infection in aseptic loosening of total hip arthroplasty. Acta Orthop. 2010. doi:10.3109/ 17453674.2010.525201.

14. Park YS, Moon YW, Lim SJ, Yang JM, Ahn G, Choi YL. Early osteolysis following second-generation metal-on-metal hip replacement. J Bone Joint Surg Am. 2005;87:1515-1521.

15. Shahrdar C, Campbell P, Mirra J, Dorr LD. Painful metalon-metal total hip arthroplasty. J Arthroplasty. 2006;21:289293.

16. Skipor AK, Campbell PA, Patterson LM, Amstutz HC, Schmalzried TP, Jacobs JJ. Serum and urine metal levels in patients with metal-on-metal surface arthroplasty. J Mater Sci Mater Med. 2002;13:1227-1234.

17. Willert HG, Buchhorn GH, Fayyazi DA, Flury R, Windler M, Koster G, Lohmann $\mathrm{CH}$. Metal-on-metal bearings and hypersensitivity in patients with artificial hip joints: a clinical and histomorphological study. J Bone Joint Surg Am. 2005;87: $28-36$. 